\title{
Play-Centric Designing of a Serious Game Prototype for Low Vision Children
}

\author{
Nurul Izzah Othman ${ }^{1}$, Nor Azan Mat Zin ${ }^{2}$, Hazura Mohamed ${ }^{3}$ \\ Faculty of Information Science and Technology \\ The National University of Malaysia \\ 43600 Bangi, Malaysia
}

\begin{abstract}
Currently, with the advancement of Information and Communications Technology (ICT), gaming industry becomes one of the fastest growing industries. This trend leads to development of serious games as alternative tool for creating effective learning experience. However, most educational applications such as serious games mainly used visuals such graphics and animations that pose challenges for low vision children. Visually impaired users especially children with low vision would face difficulty using the applications. They have problems to see highly visual elements of the games. Accessibility refers to how a certain software or application is accessible to disabled users. Several accessibility aspects should be considered when designing user interfaces for children with low vision. Thus, a game designed to fulfill their needs is needed. However, the challenge of serious game design is not only to consider users' accessibility needs, but also the playability aspects as well so that the visually impaired children can enjoy playing regardless of their disabilities. This paper presents a study on designing a low fidelity serious game prototype for low vision children using play-centric design approach, focusing on playability to obtain feedback from low vision children. Then, based on users' feedbacks, the game prototype will be refined to improve the game design.
\end{abstract}

Keywords-Serious game; play-centric design; accessibility; low vision; low fidelity prototype

\section{INTRODUCTION}

The development of Information and Communications Technology (ICT) leads to the gaming industry becoming one of the fastest growing industries. Games become the choice of younger generation. Today, games are important for leisure activities of most children. The game features will make learning become interesting and rewarding for children [1]. This trend leads to the development of serious games around the world. Serious games act as an alternative tool for creating learning experiences [2]. Serious games are digital games that have been designed with goals beyond entertainment such as for communication, defense, training, healthcare, and marketing [3]. The purpose of a serious game is basically to educate users while enabling an enjoyable experience [4]. As an example, serious games have been designed for training purposes. InfoSecure is a serious game designed to create awareness on information security [5]. Serious games are also used for health-related problems including rehabilitation, neurological disabilities, psychomotor coordination, speech problems, and obesity [6], as in the case of Kinect game for autistic rehabilitation. Besides, serious games have also been implemented in learning [7]-[9]. In learning, serious games provide benefits because they are fun and motivate students to participate in the learning activities [5]. However, how far the serious game is accessible to the disabled user is not widely studied. Accessibility refers to how a certain software or application is accessible to disabled users.

According to [10], accessibility refers to how disabled user is enabled to use ICT systems, applications, and websites. Accessibility refers to ICT systems or applications that are designed and developed so that user with disabilities can also use them. They could perceive, understand, navigate, and interact with the ICT systems. Accessibility also enables products to be more beneficial for all users and makes products more user friendly to everyone [11]. Accessibility encompasses auditory, cognitive, neurological, physical, speech, and visual components[12]. Different types of disability may become a barrier in accessing ICT applications. For example, a user with hearing impairment has difficulties to access audio while a visually impaired user has difficulties to access visual information. They have different accessibility requirements due to their disabilities. Therefore, ICT applications should be designed with the consideration of accessibility aspect so that the application can be used by users with disabilities. The user interface of ICT application is designed based on certain disabilities such as physical, cognitive, audio, and visual. For users with physical disabilities, alternative environment should be designed instead of using mouse or input to computers because they would encounter difficulties using the tools. Users with cognitive disabilities require suitable user interface to support their cognitive disabilities. Meanwhile, hearing impaired users need graphical elements on the user interface as an alternative to audio due to their disability to access audio elements. On the other hand, visual impairment may cause difficulties to access graphical elements on the user interface. Thus, visually impaired user needs audio as a visual substitute on the user interface.

Most ICT applications use graphical based interfaces. Therefore, visually impaired users especially children with low vision would face difficulty using the applications. Low vision is one of the visual impairments that causes a person to encounter difficulties in performing daily activities. Low vision occurs when the visual acuity decreases and can not be corrected by glasses or contact lenses. The level sight of a person who has low vision does not exceed $6 / 60$ or $20 / 200$ [13]. As a result, they have problems to see visual elements

*Corresponding Author 
and subsequently may encounter challenges in learning. The choice of efficient tools is important to enable children with low vision to access learning materials. Many educational applications such as serious games are based on visual and animation that pose challenges for children with low vision. According to [14],[15], the interfaces usually cause problems for them due to small text, graphic, and crowded backgrounds. They need high contrast and bright colours. Moving objects also present problems to them. Due to these issues, they need an accessible game designed to fulfill their play experience.

Despite the accessibility barriers, children with low vision should have the opportunity to play serious games like other normal children and have fun along the way. Therefore, serious game designs for them should not only consider the accessibility needs, but the playability aspects as well so that the visually impaired children can enjoy playing regardless of their disability.

Design phase is important in game development. A serious game design for children with low vision also needs to be balanced between serious purposes and gaming experience in order for them to have a chance to experience games like normal children. Thus, the prototyping stage plays an important role in designing a game. The game prototype that has been designed can be tested and redesigned iteratively based on player or user feedback. This paper presented a study to design a low fidelity serious game prototype for children with low vision using play-centric design approach. The prototype was tested for the gaming experience.

The next section of this paper presents the Literature review, followed by Methodology in Section III, Results and discussion in Section IV and finally Conclusion in Section V.

\section{LITERATURE REVIEW}

\section{A. Low Vision}

According to [13], about 1.3 billion people live with visual impairment. Visual impairment becomes a challenge for visual accessibility. Visual accessibility is not limited to blindness only. Low vision is a type of visual impairment that affects people around the world. Low vision is vision loss that affects daily activities which can differ among individuals. Eye care professionals use the term "low vision" to describe permanently reduced vision that cannot be improved with regular glasses, contact lenses or surgery.

Children with low vision have sight balance that can be assisted by using low vision aids. The aids could help someone in doing daily activities. Several low vision aids such as monoculars, magnifying lenses, and non-optic devices are used to improve the ability to see visual elements [16]. Apart from that, children with low vision use non-optical devices such as reading lights, bold line papers, and large print books. Those with low vision can also use computers and software if the interfaces are designed based on their needs. However, children with low vision has several issues that become a difficulty for them to access ICT systems or applications. They have difficulty to access visual elements on user interfaces. The contents of ICT applications such as text, graphics, and animations may be inaccessible to them. Instead, audio elements can be used to substitute visual elements [12].
Several aspects should be considered when designing user interfaces for children with low vision such as screen design, graphic presentation, text readability, and graphic colours [16]. These considerations are important to ensure they benefit from the development of technology especially serious games because everyone should have the opportunity to play serious games including children with low vision.

1) Designing serious game for low vision children: The serious game concept was introduced by Abt in 1970. He presented the use of board and card games or pen and paper based games. This concept was also presented in the form of war games during a project conducted by Atari in the 1980s for military training. Designs of a serious game are different based on target users since they are different [17]. Despite the potential of serious games, research on serious games for visually impaired users are limited because most existing games for visually impaired users are for entertainment purposes. Audio acts as a replacement for visual information in games. Thus, several audio games have been developed for visually impaired users [18]. Original games that have been modified to enable the visually impaired users to play them include Audio Quake, Rock Vibe, Terraformers, Em Busca do Santo Grau, and many others [19]-[23]. Apart from audio, haptic interactions are also used to replace visual information in games [24]. As an example, Game2senses is one of digital games which use haptic to replace visual element [25]. However, for visually impaired users such as children with low vision, they still have vision balance which enables them to play serious games like normal children if the games are designed based on their needs. The user interface should be accessible and easy to use so they can play the game rather than be stressed by the user interface. According to [15], an accessible game will provide equal opportunity for playing experience to its players. However, the gaming industry has been facing a lack of accessible games [26].

Generally, people with visual impairment could not play mainstream video games because the important game content is in the form of graphics. Therefore, several accessibility elements have been identified from literature and are described as in Table I. These elements should be considered when designing serious games for low vision children.

A serious game should be balanced between game enjoyment and serious purpose. According to [33], learning is usually considered as a serious activity and not for the purpose of fun. Nevertheless, research on serious games have shown that learning through games provide positive effects because children can learn while playing. Game becomes an effective pedagogy. Children will be bored if games are not entertaining. Children could learn and improve their skills during playing and get motivated by fun elements in games. Therefore, specific attention should be given to the game design so that children can focus and enjoy playing the game. These highlight the importance of play-centric approach in game design process. 
TABLE I. ACCESSIBILITY ELEMENTS FOR LOW VISION CHILDREN

\begin{tabular}{|c|c|}
\hline $\begin{array}{l}\text { Accessibility } \\
\text { Elements }\end{array}$ & Descriptions \\
\hline $\begin{array}{l}\text { Multimedia } \\
\text { (Audio, Text, } \\
\text { Graphics, and } \\
\text { Animation) } \\
{[15],[27]-[29]}\end{array}$ & $\begin{array}{l}\text { 1. Sound is used as accessibility element and } \\
\text { important for those with vision problems. Audio } \\
\text { instruction have to be clear. Sound recordings are } \\
\text { incorporated in dialogues, menus, and tasks. One } \\
\text { sound should be played at a time because low } \\
\text { vision children only focus on one sound at a time. } \\
\text { 2. Text-to-speech instructions should include audio. } \\
\text { 3. If the low vision children does not understand a } \\
\text { task, the task can be listened again. } \\
\text { 4. Format and style for text should use at least size } \\
\text { 5. The colour combinations for fonts and } \\
\text { backgrounds are very contrasting. } \\
\text { 6. The best type of text for visually impaired } \\
\text { 7. } \begin{array}{l}\text { Inform is Serif. } \\
\text { bigger }\end{array} \\
\text { 8. Use of bright colour }\end{array}$ \\
\hline $\begin{array}{l}\text { Navigation } \\
{[27],[30]-[32]}\end{array}$ & $\begin{array}{l}\text { 9. Menu layout should be simpler in design. } \\
\text { 10. Start button and menu should include audio to } \\
\text { assist navigation. }\end{array}$ \\
\hline $\begin{array}{l}\text { Language } \\
{[28],[31]}\end{array}$ & 11. Use language that user can understand. \\
\hline Object Speed [31] & $\begin{array}{l}\text { 12. Animation movements should be slower for low } \\
\text { vision children } \\
\text { 13. Animation movements should be in the same } \\
\text { direction and not the opposite. }\end{array}$ \\
\hline $\begin{array}{l}\text { Screen Design } \\
{[28][30]}\end{array}$ & $\begin{array}{l}\text { 14. Simple screen design that reduces children's } \\
\text { cognitive load. The user interface is easy to be } \\
\text { adapted for low vision children. }\end{array}$ \\
\hline
\end{tabular}

\section{B. Play-Centric Design}

According to [34], play-centric design is an approach that puts player experience as a priority in the design process that creates audience involvement with meaningful interactions and complex storylines. It is an iterative method that depends on feedback from players at the early stage of design process. Ideas on satisfying gaming experience are generated during the initial process. In play-centric design, ideas are prototyped and playtested during the design phase. Prototyping is important in the early stages of game design and becomes a tool for playtesting. Prototypes allow designers to obtain feedback from users and get ideas. Prototyping is an important part in design process in order to understand player experience. Different approaches include paper prototyping, physical prototyping, scenario writing, and interactive prototyping. Prototype also acts as a basis for playtesting. Playtesting is conducted during design process to identify whether the game achieves player expectations and obtain feedback regarding the play experience. There are several ways to conduct playtesting such as informal and qualitative. Table II shows several methods for playtesting.

By prototyping and playtesting, tester will know whether the prototype is playable or not. Therefore, play-centric design is important in game design and development. Based on the approach, the game prototype that has been designed will be tested and redesigned based on tester feedback. Next section discusses the methodology in this study.
TABLE II. Playtesting MethodS

\begin{tabular}{|l|l|}
\hline Playtesting Methods & Descriptions \\
\hline One on one testing & $\begin{array}{l}\text { Testing is conducted with individuals, where tester } \\
\text { watches them play the game. }\end{array}$ \\
\hline Group testing & $\begin{array}{l}\text { Testing is conducted with a group of people which } \\
\text { allows them to play together and ask questions }\end{array}$ \\
\hline Feedback Forms & $\begin{array}{l}\text { Testing is conducted by giving each person who play } \\
\text { the game a set of questions to answer after playing. }\end{array}$ \\
\hline Interview & $\begin{array}{l}\text { Tester sits down face to face with playtesters and } \\
\text { give an interview after the testing session. }\end{array}$ \\
\hline Open discussion & $\begin{array}{l}\text { One on one discussion or group discussion after } \\
\text { playtesting session where tester guides the } \\
\text { conversation and prepares specific questions. }\end{array}$ \\
\hline
\end{tabular}

\section{METHODOLOGY}

The accessibility elements were applied to the game design. so that the storyline could be easily understood by children. Language is an important element in order to enhance accessibility. In this game, Malay language was used as a medium to convey the game content. The multimedia elements were presented in the storyline with bigger character sizes and using bright colours. The size of text used to convey the storyline should be bigger and the colour for the character and text should be in high contrast with the background colour. The storyline should also be accompanied with background audio. Furthermore, in the game design, the multimedia elements should be adapted with the fantasy elements where the game environment should use bright colours and have high contrast between the graphics and background colour. The graphics for fantasy elements should also be minimal. In order to design rewards for the game, the text size should be bigger and accompanied with background audio. The colours used for graphics should be bright and have high contrast. The challenges should be adapted to the children's ability. Meanwhile, graphics, animations, and audio were incorporated into the challenges with bigger graphic size, bright colours, and audio instructions for the tasks. Audio can also be used for guidance in game obstacles. The game's objective should be clear and included in the background audio so that children with low vision can understand it.

Apart from the accessibility aspect, gaming experience is important in order to ensure the children have fun and improve the playability of the game. Based on the play-centric design approach, there are four phases involved: conception phase, design and prototyping, playtesting, and implementation.

\section{A. Serious Game Design and Prototyping}

The design of serious game starts with conception phase. There are several game aspects to be identified in this phase such as objective, genre, content, character, storyline, gameplay, theme, and target player. In designing a serious game for children with low vision, the intention is to avoid them from getting stressed during playing. The children should feel entertained and comfortable while learning. We chose an adventure game and set the storyline in the animal kingdom by generating simple conflicts between the animals. This serious game is a math game that targets children with low vision aged seven years old. Friendship and kindness among friends are the theme for this game. This game was 
developed for Android tablets. The storyline of this game is about a rabbit named "Bunny" who tries to save his friends who are kidnapped by a tiger. Bunny needs to complete the tasks provided for each level in order to get clues and tools to be used in the next challenges. The clues and tools will assist Bunny to save his imprisoned friends from the tiger. The game environment revolves around the animal kingdom which consists of a jungle, rivers, and an old palace. Other characters in the game are monkey, bear, tiger, and turtle who help Bunny to save his friends. Animals are selected because children can identify better with animal characters [35], [36].

The game content involves mathematical subject for Primary Levels 1 (7 years old) and 2 (8 years old) which consists of three levels. The player will control the main character with the aim to save his friends who were kidnapped by the tiger. The results of the player's actions will culminate to the completion of each level. Fig. 1 shows the serious game flowchart.

The game starts with a brief introduction scene where Bunny is seen playing with monkey and bear in an area near the forest when a tiger comes and kidnaps the monkey and bear. Bunny is sad and meets a turtle. According to the turtle, Bunny needs to finish mathematical tasks if he wants to find the tiger's place and release his friends. Level 1 starts thereafter. The player's first challenge is to choose the way to the tiger's place. The player is required to complete the task of recognising numbers. Upon completion of the task, guidance is given to the player to go to the place of the tiger. Then, he faces the next obstacle, the lion. The player needs to complete the subsequent tasks in order to get to the second level. The player will get marks and stars for every task that has been successfully completed.

At the second level, the first challenge starts when the player wants to cross the lake. To cross the lake, he/she needs to complete the task of recognising geometric shapes. Upon completion of the task, the player will cross the lake with a given boat. The player will face the next obstacle - a big rock that blocks the journey. The player needs to complete another set of geometric shapes task. After successfully completing the task, the big rock is moved to the side and the player continues the journey.

The player proceeds to the third level. At the third level, the player goes to an old castle. He/she needs to choose between two doors to enter the castle. He/she has to complete mathematical operations task. After successfully completing the task, direction is provided and the player goes to the correct door. The player meets his friends which are monkeys and bears imprisoned in a cage. To free his friends from the cage, the player needs to answer another set of mathematical operations. Upon completion of the task, the player gets the key to unlock the cage.

Therefore, based on gameplay ideas, designs, and storyline, a low fidelity prototype was produced. Prototype is used to test the ideas and game playability in order to assess its usability and needs for improvement. The low fidelity prototype was a storyboard. Fig. 2 shows samples of the low fidelity prototype.

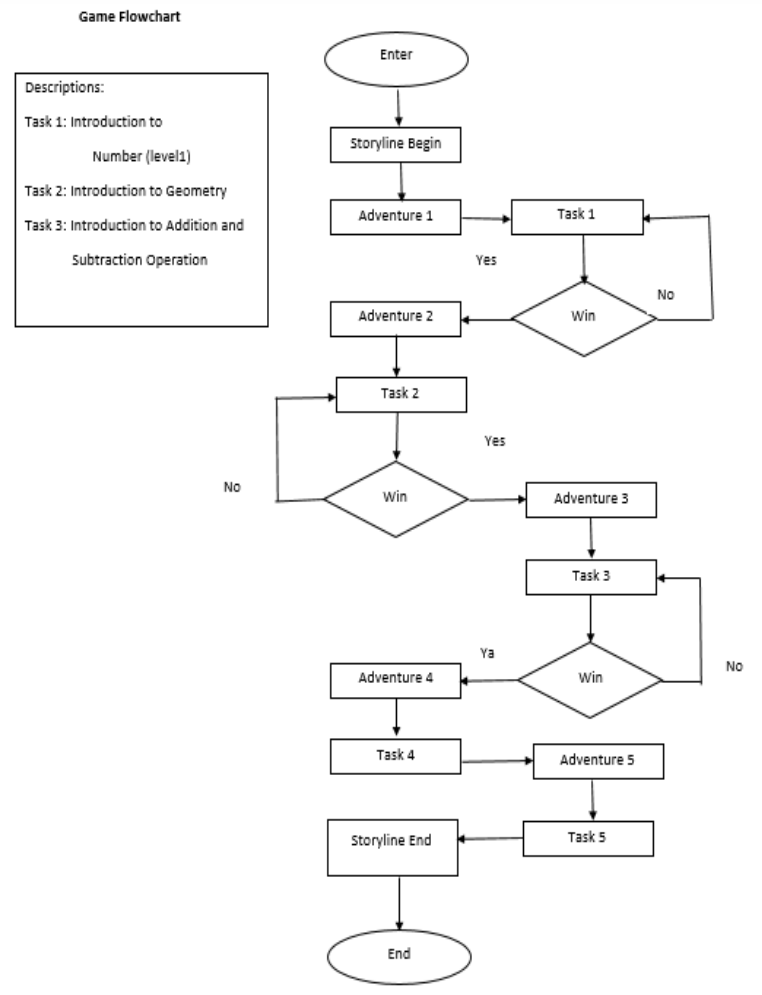

Fig. 1. Serious Game Flowchart.

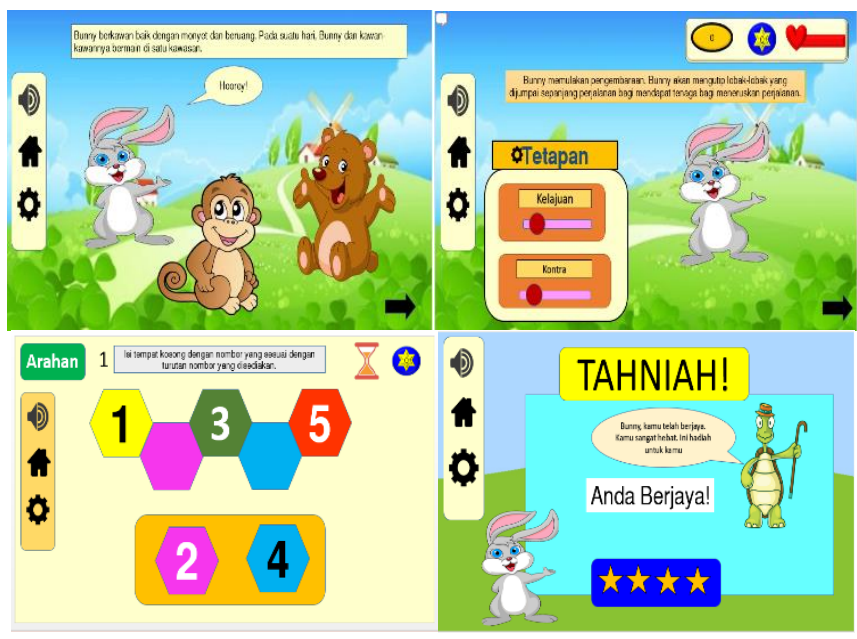

Fig. 2. Sample Screens of Low Fidelity Prototype.

\section{B. Playtesting}

Playtesting method is conducted after the design and prototyping phase to elicit feedback from users regarding their play experience. In this study, playtesting was conducted informally and qualitatively. This method was used to enable users to play more comfortably. The goal of this play test was to get feedback on their play experience including problems affecting the experience. Normal children were selected for playtesting because they can give feedback on the game design and playability based on their gaming experience. Normal children could be selected when it is difficult to engage with real end-users [37]. The playtesting procedures for the study are as follows: 
- Procedures were started with the researchers introducing themselves and explaining the purpose of the playtesting.

- Researchers introduced game prototypes to testers.

- Observation began with researchers asking the children to play the low fidelity prototype.

- This playtesting involved six children with digital gaming experience.

- Players played in pairs where they can talk while playing the game. They were asked to think aloud during playing.

- The play session was recorded.

- After the session, a focus group was conducted with the testers to get their feedback on the game.

- The feedback from the playtesting were used to refine the prototype.

Fig. 3 shows the playtesting process with children.

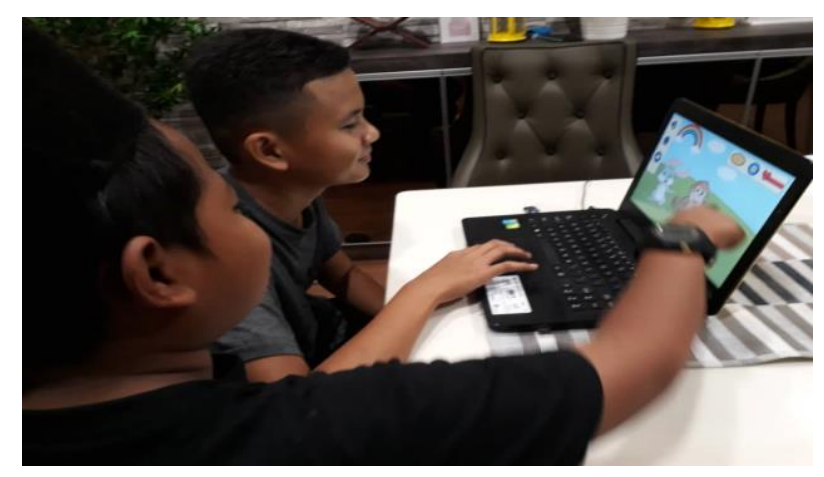

Fig. 3. Playtesting Process with Children.

Fig. 4 shows the summary of game design process.

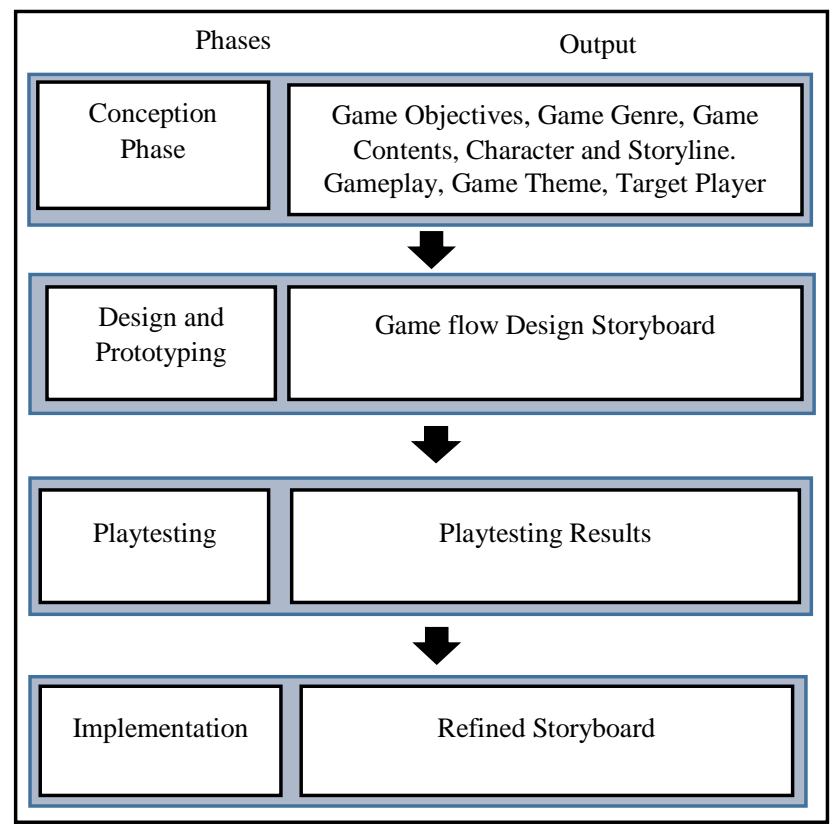

Fig. 4. Game Design Process.

\section{RESULTS AND DISCUSSION}

Based on the observation, the players took about 25 minutes to complete all three levels of the game. According to the players, the game was fun as they can play while learning and thinking. Table III presents results from the playtesting.

TABLE III. Playtesting ResUlts

\begin{tabular}{|l|l|}
\hline Game Aspects & Playtesting Results \\
\hline $\begin{array}{l}\text { Gaming } \\
\text { Experiences }\end{array}$ & $\begin{array}{l}\text { The respondents took around } 25 \text { minutes to complete all } \\
\text { three levels of the game. } \\
\text { The respondents indicated that the game was fun to play. } \\
\text { They can also play while learning and thinking. }\end{array}$ \\
\hline Storyline & Easy to understand. \\
\hline Challenges & $\begin{array}{l}\text { The tasks need to include time to complete a task. } \\
\text { At Level 3, a guard must be placed at the castle. }\end{array}$ \\
\hline Rewards & $\begin{array}{l}\text { Rewards should also be added in a more attractive form. } \\
\text { When doing a task, praise should be given to players. }\end{array}$ \\
\hline Game Interface & $\begin{array}{l}\text { Graphics and colours are suitable for children. } \\
\text { The game interface is easy to navigate. } \\
\text { The 'next' button on the game interface needs to be } \\
\text { changed to make it clearer to the player. }\end{array}$ \\
\hline
\end{tabular}

According to the players, the game storyline was easy to understand. In terms of the challenges, each task should include time limit to complete it. At level 3, a guard must be placed at the castle. Rewards should also be presented in a more attractive form. Upon finishing a task, compliments should be given to players. On the aspect of game interface, according to the testers, the graphics and colours were suitable for children. The game interface was also easy to navigate. However, the 'next' button on the game interface should be changed to make it clearer to players. The following figures show the aspects of the prototype that had been refined based on the players' feedback.

- Each task should have time limit to complete it (Challenge) as shown in Fig. 5.

- A guard should be placed at the door to improve the element of challenge in the game as shown in Fig. 6. If the task fails to be completed, Bunny will be captured by the guard.

- Positive feedback is given each time a task is completed as shown in Fig. 7.

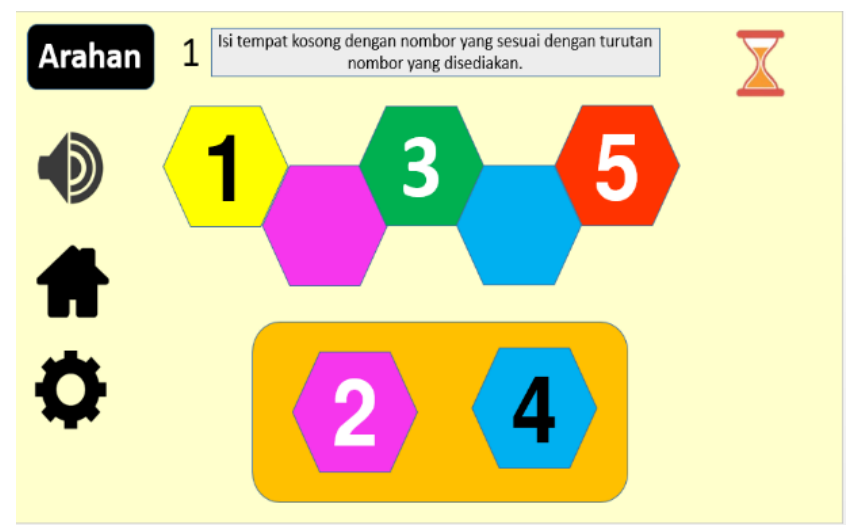

Fig. 5. The Hourglass shows the Amount of Time it Takes to Complete the Task. 


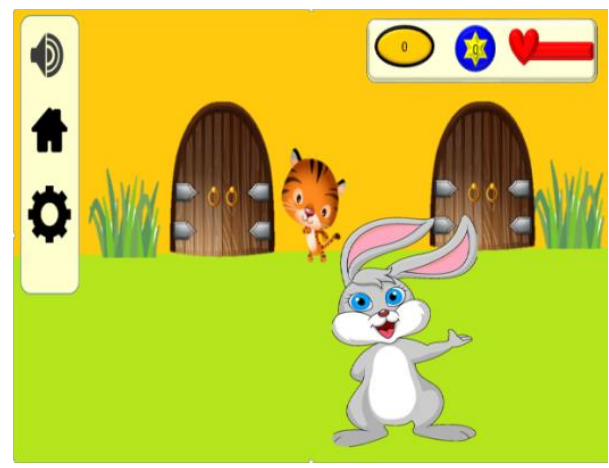

Fig. 6. A Guard at the Door.

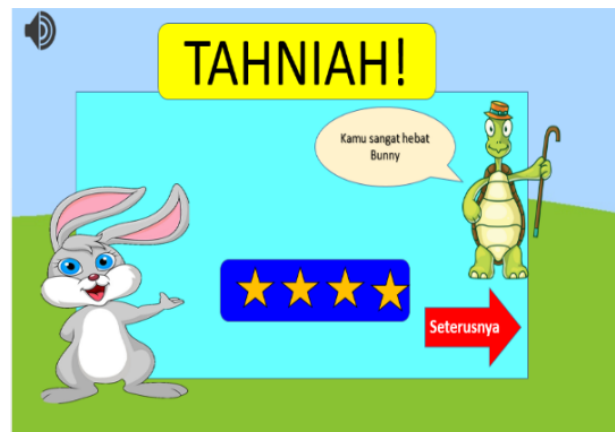

Fig. 7. Positive Feedback - Praise for Encouragement.

- The existing 'star' badge can be used to assist future tasks as shown in Fig. 8. The number on the 'star' badge increases upon successful completion of the previous task.

- Rewards should be presented in a more attractive form. Fig. 9 shows the rewards after completing tasks.

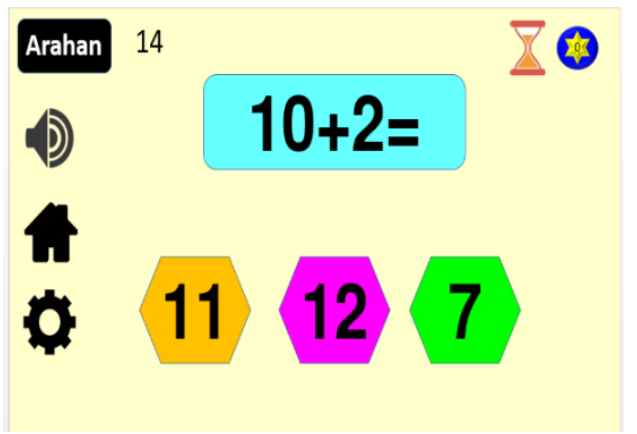

Fig. 8. The Existing 'Star' Badge can be used to Assist Future Tasks.

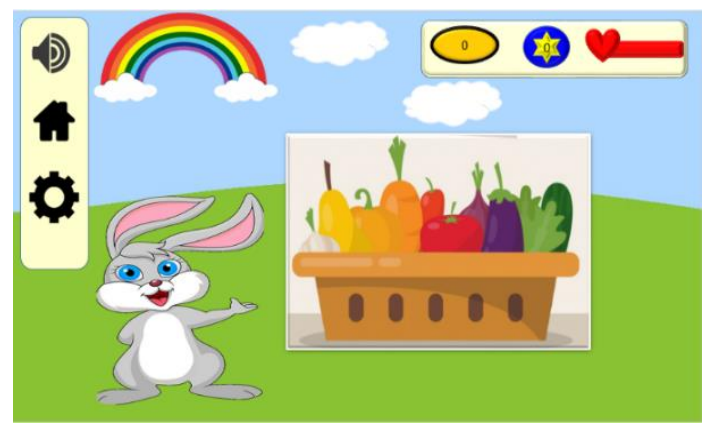

Fig. 9. Rewards after Completing Tasks.

\section{CONCLUSION}

This paper presents a study on designing a low fidelity serious game prototype for low vision children using playcentric design approach in order to obtain feedback on game playability from children. In this study, ideas are prototyped and playtested. Children are involved at the early stage of the design process. They contributed game ideas to improve the playability of the game. Thus, play-centric design approach is important to ensure playbility and good gaming experience. A serious game should be balanced between playability and serious purpose to ensure the children will have fun and motivated when playing game. Based on testers feedbacks, there are several game aspects that should be improved such as gaming experiences, storylines, challenges, rewards, and game interface. Future work will involve refining the game prototype which will be verified using heuristic evaluation and finally the development of final high fidelity game prototype.

\section{ACKNOWLEDGMENT}

The authors would like to acknowledge UKM for the publication sponsorship under grant PP-FTSM-2020 and the Ministry of Higher Education for sponsorship under MyBrain15 programme.

\section{REFERENCES}

[1] N. Azli, M. Masrop, H. Ishak, G. Zainuddin, and S. R. Ramlan, "Digital Games Based Language Learning for Arabic Literacy Remedial," Creat. Educ., vol. 10, pp. 3213-3222, 2019.

[2] S. Cano, U. Cauca, J. M. Arteaga, U. Cauca, and V. B. Amador, "Model for Analysis of Serious Games for Literacy in Deaf Children from a User Experience Approach," in Interacción '15 Proceedings of the XVI International Conference on Human Computer Interaction, 2015.

[3] R. Dorner and U. Spierling, "Serious Games Development as a Vehicle for Teaching Entertainment Technology and Interdisciplinary Teamwork: Perspectives and Pitfalls," in SeriousGames '14 Proceedings of the 2014 ACM International Workshop on Serious Games, 2014, pp. 3-8.

[4] L. He, X. Hu, and D. Wei, "The Case Analysis of Serious Game in Community Vocational Educationl," Int. Conf. Comput. Sci. Netw. Technol., 2011, pp. 1863-1866.

[5] A. Ghazvini and Z. Shukur, "A Serious Game for Healthcare Industry: Information Security Awareness Training Program for Hospital Universiti Kebangsaan Malaysia," Int. J. Adv. Comput. Sci. Appl., vol. 9, no. 9, pp. 236-245, 2018.

[6] A. Shapi'i, N. A. A. Rahman, M. S. Baharuddin, and M. R. Yaakub, "Interactive Games using $\mathrm{h}=$ Hand-e=Eye Coordination Method for Autistic Children Therapy," Int. J. Adv. Sci. Eng. Inf. Technol., vol. 8, no. 4-2, pp. 1381-1386, 2018.

[7] N. A. M. Zin, A. Jaafar, and S. Y. Wong, "Digital Game-Based Learning (DGBL) Model and Development Methodology for Teaching History," WSEAS Trans. Comput., vol. 8, no. 2, pp. 322-333, 2009.

[8] N. M. Diah, N. A. M. Zin, "Interactive Writing Tool for Jawi Literacy," vol. 7, no. October, pp. 48-57, 2013.

[9] N. Zainuddin, A. Ab. Rahman, M. S. Sahrir, and H. A. Khafiz, "A Study on the Effectiveness of Global Zakat Game (GZG) as a Zakat Teaching and Learning Tool," Int. J. Acad. Res. Bus. Soc. Sci., vol. 9, no. 3, pp. 1488-1500, 2019.

[10] Katie Cunningham, Accessibility Handbook. 2012.

[11] S. Z. Mohid and N. A. M. Zin, "Courseware Accessibility for Hearing Impaired," Information Technology (ITSim), in 2010 International Symposium, 2010, pp. 26-30.

[12] The World Wide Web Consortium, "World Wide Web Consortium," 2018. [Online]. Available: https://www.w3.org/. [Accessed: 15-Feb2018]. 
[13] World Health Organization, "World Health Organization," 2017. [Online]. Available: http://www.who.int/mediacentre/factsheets/fs282/ en/. [Accessed: 01-Mar-2017].

[14] N. I. Othman, N. A.M. Zin, and H. Mohamed, "Accessibility Requirements In Serious," in 2019 International Conference on Electrical Engineering and Informatics (ICEEI), 2019.

[15] I. Dela Torre and I. Khaliq, "A Study on Accessibility in Games for The Visually Impaired," in 2019 IEEE Games, Entertain. Media Conf. GEM 2019, 2019, pp. 1-7.

[16] S. R. Vaughn, C. S. Bos, and J. S. Schumm, Teaching Students Who Are Exceptional, Diverse, and at Risk. 2003.

[17] S. R. Z. Abidin, S. F. M. Noor, and N. S. Ashaari, "Low-Fidelity Prototype Design for Serious Game for Slow-reading Students," Int. J. Adv. Comput. Sci. Appl., vol. 10, no. 3, pp. 270-276, 2019.

[18] T. Westin, K. Bierre, D. Gramenos, and M. Hinn, "Advances in Game Accessibility from 2005 to 2010," 6th International Conference, UAHCI, 2010, pp. 400-409.

[19] L. V. Neto, P. H. Fontoura Junior, R. A. Bordini, and J. L. Otsuka, "Design and implementation of an educational game considering issues for visual impaired people inclusion," Proc. - IEEE 19th Int. Conf. Adv. Learn. Technol. ICALT 2019, no. Dc, pp. 298-302, 2019.

[20] M. T. Atkinson, C. H. C. Machin, and A. E. Lawrence, "Making the Mainstream Accessible: Redefining the Game," ACM SIGGRAPH Symp. Videogames, vol. 1, no. 212, pp. 21-28, 2006.

[21] D. Archambault, R. Ossmann, T. Gaudy, K. Miesenberger, I. Inova, and S. Bernard, "Computer Games and Visually Impaired People," pp. 1-21, 2008.

[22] G. R. White and G. Mcallister, "Toward Accessible 3D Virtual Environments for the Blind and Visually Impaired," in DIMEA '08: Proceedings of the 3rd International Conference on Digital Interactive Media in Entertainment and Arts 2008, pp.134-141.

[23] D. Grammenos, A. Savidis, and C. Stephanidis, "Designing universally accessible games," Comput. Entertain., vol. 7, no. 1, p. 1, 2009.

[24] M. De Pascale, S. Mulatto, and D. Prattichizzo, "Bringing Haptics to Second Life for Visually Impaired People," in International Conference on Human Haptic Sensing and Touch Enabled Computer Applications, pp 896-905, 2008.

[25] P. Escudeiro, N. Escudeiro, P. Oliveira, and M. Barbosa, "Blind's Inclusion in Mobile Games," in 2017 27th EAEEIE Annual Conference (EAEEIE), 2017, pp. 1-5.
[26] D. Mcpheron, "Video Gaming Accessibility," in The 20th International Conference on Computer Games, 2015, pp. 1-5.

[27] R. Baguma and J. T. Lubega, "A Web Design Framework for Improved Accessibility for People with Disabilities ( WDFAD )," in W4A '08: Proceedings of the 2008 international cross-disciplinary conference on Web accessibility, 2008, pp. 134-140.

[28] Z. Sun and J. Wen, "Exploration of Chinese Website Accessibility Evaluation Model," in International Conference on Computer Science and Software Engineering, 2008, pp. 1357-1360.

[29] N. Aziz, A. A. Mutalib, and S. M. Sarif, "The design principles of assistive courseware for low vision (AC4LV) learners," ARPN J. Eng. Appl. Sci., vol. 10, no. 3, pp. 1447-1456, 2015.

[30] C. Perrenoud and K. Phan, "Emergence of Web Technology: An Implementation of Web Accessibility Design in Organizations," in Proceedings of PICMET'12: Technology Management for Emerging Technologies, 2012, pp. 633-645.

[31] Z. Sun and J. Wen, "Exploration of Chinese Website Accessibility Evaluation Model," in International Conference on Computer Science and Software Engineering, 2008, pp. 1357-1360.

[32] M. S. Hassouna, N. Sahari, and A. Ismail, "University website accessibility for totally blind users," J. Inf. Commun. Technol., vol. 16, no. 1 , pp. 63-80, 2017.

[33] A. F. S. Barbosa and F. G. M. Silva, "Serious Games - Design and Development of OxyBlood," in Proceedings of the 8th International Conference on Advances in Computer Entertainment, 2011, pp. 1-8.

[34] T. Fullerton, GAME DESIGN WORKSHOP A Playcentric Approach to Second Edition, 2nd ed. Elsevier Inc., 2008.

[35] R. Raisamo, S. Patomäki, M. Hasu, and V. Pasto, "Design and evaluation of a tactile memory game for visually impaired children," Interact. Comput., vol. 19, no. 2, pp. 196-205, 2007.

[36] E. Sudarmilah, A. Susanto, R. Ferdiana, and N. Ramdhani, "Developing a game for preschoolers: What character, emotion and reward will tend to hack preschoolers?," in Proc. 2015 Int. Conf. Data Softw. Eng. ICODSE 2015, 2016, pp. 89-92.

[37] M. A. Lievesley and J. S. R. Yee, "Surrogate users: A Pragmatic Approach to Defining User Needs," in Conf. Hum. Factors Comput. Syst. - Proc, 2007, pp. 1789-1794. 